\title{
What are the differences in the outcome of laparoscopic axial (I) versus paraesophageal (II-IV) hiatal hernia repair?
}

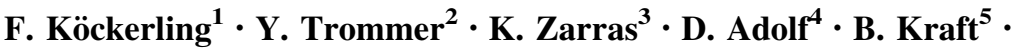 \\ D. Weyhe $^{6} \cdot$ R. Fortelny ${ }^{7}$ C. Schug-Paß ${ }^{1}$
}

Received: 24 January 2017/ Accepted: 16 May 2017/Published online: 8 June 2017

(C) The Author(s) 2017. This article is an open access publication

\begin{abstract}
Introduction Comparison of elective laparoscopic repair of axial vs paraesophageal hiatal hernias reveals relevant differences in both the patient collectives and the complexity of the procedures.

Materials and methods The present uni- and multivariable analysis of data from the Herniamed Registry compares the outcome for 2047 (67.3\%) (type I) axial with 996 (32.7\%) (types II-IV) paraesophageal primary hiatal hernias following laparoscopic repair.

Results Compared with the patients with axial hiatal hernias, patients with paraesophageal hiatal hernia were nine
\end{abstract}

F. Köckerling

ferdinand.koeckerling@vivantes.de

1 Department of Surgery and Center for Minimally Invasive Surgery, Academic Teaching Hospital of Charité Medical School, Vivantes Hospital, Neue Bergstrasse 6, 13585 Berlin, Germany

2 Department of General, Visceral and Minimally Invasive Surgery, Helios Hospital, Campus 6, 38518 Gifhorn, Germany

3 Department of Visceral, Minimally Invasive and Oncologic Surgery, Marien Hospital, Rochusstrasse 2, 40479 Düsseldorf, Germany

4 StatConsult GmbH, Halberstädter Strasse 40 A, 39112 Magdeburg, Germany

5 Department of General and Visceral Surgery, Diakonie Hospital, Rosenbergstrasse 38, 70176 Stuttgart, Germany

6 Department of General and Visceral Surgery, Pius Hospital, University Hospital of Visceral Surgery, Georgstrasse 12, 26121 Oldenburg, Germany

7 Department of General, Visceral and Oncologic Surgery, Wilhelminenhospital, Montleartstrasse 37, 1160 Vienna, Austria years older, had a higher ASA score (ASA III/IV: 34.8 vs $13.7 \% ; p<0.001)$, and more often at least one risk factor (38.8 vs $21.4 \% ; p<0.001)$. This led in the univariable analysis to significantly more general postoperative complications (6.0 vs $3.0 \% ; p<0.001)$. Reflecting the greater complexity of the procedures used for laparoscopic repair of paraesophageal hiatal hernias, significantly higher intraoperative organ injury rates (3.7 vs $2.3 \% ; p=0.033$ ) and higher postoperative complication-related reoperation rates ( 2.1 vs $1.1 \% ; p=0.032)$ were identified. Univariable analysis did not reveal any significant differences in the recurrence and pain rates on one-year follow-up. Multivariable analysis did not find any evidence that the use of a mesh had a significant influence on the recurrence rate.

Conclusion Surgical repair of paraesophageal hiatal hernia calls for an experienced surgeon as well as for corresponding intensive medicine competence because of the higher risks of general and surgical postoperative complications.

Keywords Hiatal hernia - Fundoplication - Hiatoplasty · Axial hiatal hernia $\cdot$ Paraesophageal hiatal hernia

Four anatomic patterns of hiatal hernia can be recognized. Axial or sliding (type I) hernia, in which the gastroesophageal junction migrates into the thorax, is the most common type of hiatal hernia (95\%) and may predispose to gastroesophageal reflux [1]. Type II represents a true paraesophageal hernia with herniation of the gastric fundus anterior to a normally positioned esophagogastric junction [1]. Type III, with both elements of types I and II hiatal hernia, tends to be large with more than $50 \%$ of the stomach within the mediastinal sac [1]. In type IV hernias, the stomach, sometimes with other viscera such as the colon or spleen, migrates completely in the hernia sac, 
which may result in an "upside-down stomach" [1]. Patients with an axial/sliding or type I hernia and long-term treatment of gastroesophageal reflux disease and continuous reduced quality of life, persistent troublesome symptoms, and/or progression of disease despite adequate proton pump inhibitor therapy in dosage and intake are the best candidates for surgery [2]. Although paraesophageal hernias types II-IV account for only 5\% of all hiatal

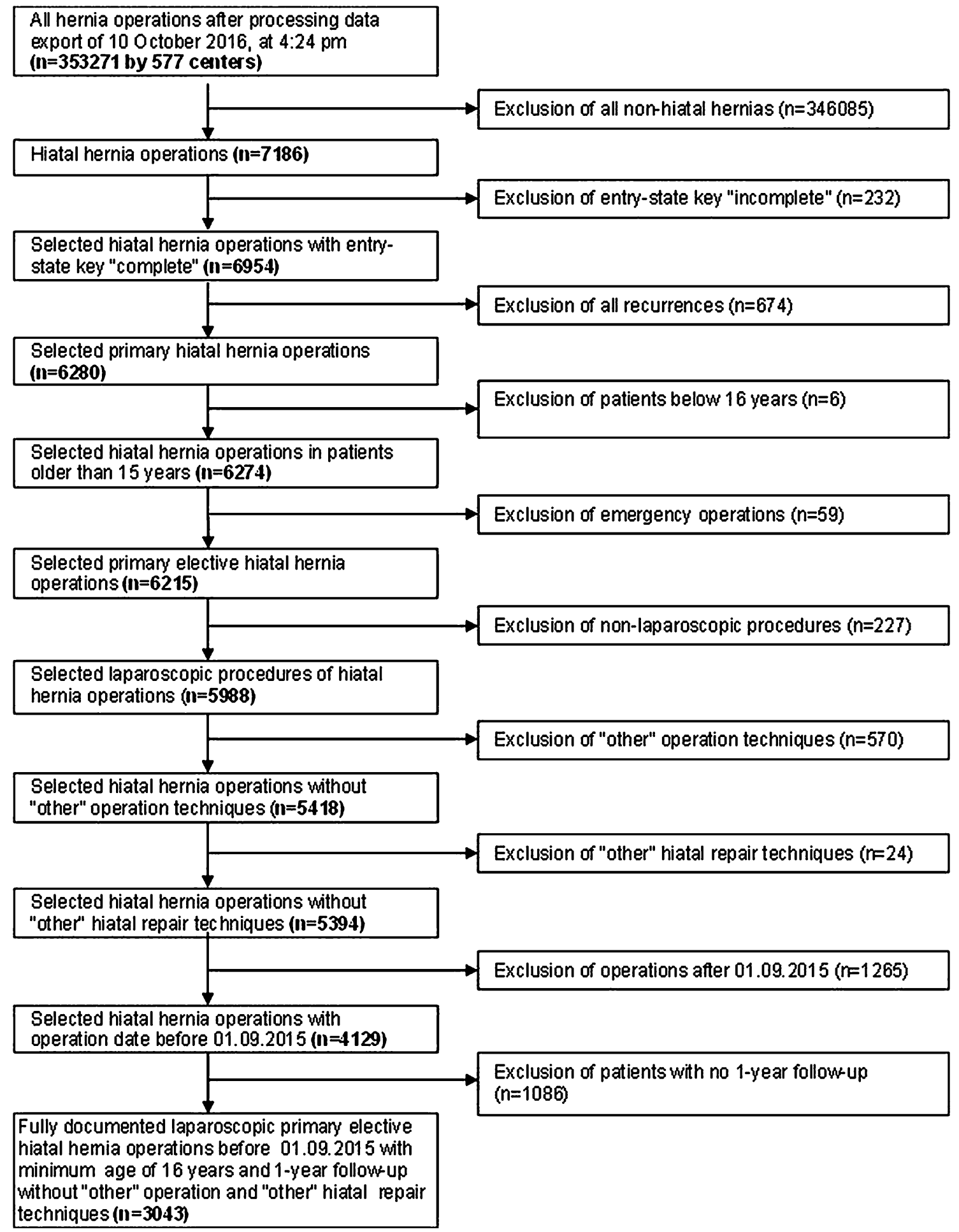

Fig. 1 Flowchart of patient inclusion 
hernias, their detection is important because of potentially life-threatening complications, such as obstruction, acute dilatation, perforation, or bleeding of the stomach mucosa [1]. In essence, no conventional options are available for the treatment of paraesophageal hernia, so surgical repair is recommended for relief of symptoms [1].

Laparoscopic hiatal hernia repair is as effective as open transabdominal repair, with a reduced rate of perioperative morbidity and with shorter hospital stays. It is the preferred approach for the majority of hiatal hernias [3-6]. Laparoscopic posterior fundoplication is given preference over laparoscopic anterior fundoplication due to a lower recurrence rate [7] in the treatment of gastroesophageal reflux disease. Thirteen randomized controlled trials with 1564 patients showed for Toupet versus Nissen fundoplication significantly lower rates of adverse results involving dysphagia, gas-bloat syndrome, inability to belch, and reoperation due to severe dysphagia $[8,9]$. Mesh application should be considered for large hiatal hernia repair because it reduces recurrences, at least in the midterm. Overall, procedure-related complications and mortality do not seem to be increased despite potential mesh-associated complications [10-17].

In the literature, there is only one publication with a large case series which compares the patient collective, treatment, and the outcome of laparoscopic repair of type I hiatal hernias with those of paraesophageal hiatal hernias (types II-IV) [18]. In that study, most of the complications occurred in patients with paraesophageal compared with axial hernia (10 vs $1 \%$, respectively) [18]. This variation reflects significant differences between patients with axial hiatal hernia, and gastroesophageal reflux disease, and those with paraesophageal hernia; it also highlights the increased complexity of the laparoscopic repair procedure used for paraesophageal hernia [18]. Based on data from the Herniamed Hernia Registry, this paper now explores the differences between these patients in terms of demographic characteristics, treatment, and outcome.

\section{Materials and methods}

The Herniamed quality assurance study is a multicenter, internet-based hernia register [19] into which 577 participating hospitals and surgeons engaged in private practice (Herniamed Study Group) in Germany, Austria, and Switzerland (status: October 10, 2016) have entered data prospectively on their patients who had undergone routine surgery and signed an informed consent agreeing to participate. As part of the information provided to patients regarding participation in the Herniamed Quality Assurance Study, all patients are informed that the treating hospital would like to be informed about any problems occurring after the operation and that the patient has the opportunity to attend for clinical examination. All
Table 1 Distribution of cases based on hiatal hernia type

\begin{tabular}{lrl}
\hline Type & \multicolumn{1}{l}{$N$} & $\%$ \\
\hline Axial I & 2047 & 67.3 \\
Paraesophageal II & 263 & 8.6 \\
Mixed III & 279 & 9.2 \\
Upside-down IV & 454 & 14.9 \\
Total & 3043 & 100 \\
\hline
\end{tabular}

postoperative complications occurring up to 30 days after surgery are recorded. On one-year follow-up, postoperative complications are once again reviewed when the general practitioners and patients complete a questionnaire. On one-year follow-up, general practitioners and patients are also asked about any recurrent symptoms, pain at rest, pain on exertion, and chronic pain requiring treatment. If recurrent symptoms or chronic pain are reported by the general practitioners or patients, patients can be requested to attend for clinical examination or radiologic tests. A recent publication has provided impressive evidence of the role of patient-reported outcomes in hernia surgery [20]. The present analysis compares the prospective data collected for all patients with a hiatal hernia (types I-IV) and laparoscopic repair. Inclusion criteria were minimum age of 16 years, primary elective laparoscopic operation, fundoplication or fundophrenicopexy, and availability of data on one-year follow-up. In total, 3043 patients were enrolled from 197 participating institutions with mean number of 15.4 (range 1-199) cases between September 1, 2009 and September 1, 2015 (Fig. 1). Of these patients, 2047 (67.3\%) had an axial/sliding (type I) and 996 (32.7\%) a paraesophageal (types II-IV) hiatal hernia (Table 1). No details of the diagnostic method used for classification of hernia type were included in the registry. The demographic parameters included age (years), gender, symptoms, ASA score (I, II, III, IV), body mass index (BMI) $\left(\mathrm{kg} / \mathrm{m}^{2}\right)$, and risk factors (COPD, diabetes, aneurysms, cortisone, immunosuppression, etc.). Risk factors were dichotomized, i.e., "yes" if a risk factor was positive and "no" otherwise.

The second group of categorical influence variables reflecting surgery-related parameters included defect size, operation technique (Toupet vs Nissen vs fundophrenicopexy), and hiatoplasty (suture vs mesh vs suture and mesh).

The dependent variables were intra- and postoperative complication rates, complication-related reoperation rates, recurrence rates and rates of pain at rest, pain on exertion, and chronic pain requiring treatment.

All analyses were performed with the software SAS 9.4 (SAS Institute Inc. Cary, NC, USA) and intentionally calculated to a full significance level of 5\%, i.e., they were not corrected in respect of multiple tests, and each $p$ value $\leq 0.05$ represents a significant result. To discern differences between the groups in unadjusted analyses, Fisher's exact 
test was used for categorical outcome variables, and the robust $t$ test (Satterthwaite) for continuous variables. To rule out any confounding of data caused by different patient characteristics, the results of univariable analyses were verified via multivariable analyses in which, in addition to hiatal hernia type, other influence parameters were simultaneously reviewed.

To access influence factors in multivariable analyses, the binary logistic regression model for dichotomous outcome variables was used. Estimates for odds ratio (OR) and the corresponding $95 \%$ confidence interval based on the Wald test were given. For influence variables with more than two categories, all pairwise odds ratios were given. For age (years), the 10-year OR estimate, for BMI $\left(\mathrm{kg} / \mathrm{m}^{2}\right)$, the five-point OR, and, for defect size, the ten-point OR estimate were given. For the procedure time (min) and hernia defect size $\left(\mathrm{cm}^{2}\right)$, a logarithmic transformation was applied and re-transformed mean values and ranges specified. The results of multivariable analyses are presented in tabular form, sorted by descending impact.

\section{Results}

\section{Univariable analyses}

Patients with axial hiatal hernia (type I) and reflux disease compared with patients with paraesophageal hiatal hernia (types II-IV) were on average more than nine years younger, had a somewhat lower BMI, markedly shorter procedure time, and smaller hernia defects (Table 2).

As regards the axial hiatal hernias (type I), Toupet fundoplication (56.2 vs $41.0 \% ; p<0.001)$ as well as hiatoplasty with suture alone were performed more often (81.5 vs $64.1 \% ; p<0.001$ ) (Table 3 ). Besides, axial hiatal hernia was associated with lower ASA scores and a greater number of male patients (Table 3). On the other hand, for the paraesophageal hiatal hernias (types II-IV), more cases of fundophrenicopexy (19.5 vs $2.5 \% ; p<0.001)$ and of hiatal closure with suture and mesh (35.2 vs $17.7 \%$; $p<0.001$ ) were observed (Table 3). For the paraesophageal hernias (types II-IV), higher ASA scores (ASA III/IV: 34.8 vs $13.7 \% ; p<0.001)$ as well as more female patients $(67.2$ vs $56.2 \% ; p<0.001)$ were identified.
Besides, the proportion of patients with at least one risk factor was significantly higher for paraesophageal hernias at 30.8 vs $21.4 \%(p<0.001)$. In terms of symptoms, only reflux $(89.3$ vs $66.0 \% ; p<0.001)$ was more common for axial hiatal hernias (Table 3 ).

On overall assessment of the intraoperative complication rates no difference was detected between the axial (type I) and paraesophageal hiatal hernias (types II-IV) (Table 4). However, organ injuries were seen significantly more often with paraesophageal hiatal hernias (types IIIV) (3.7 vs $2.3 \% ; p=0.033)$.

As regards the postoperative surgical complications, no significant difference was detected between the axial (type I) and paraesophageal hiatal hernias (types II-IV). However, more complication-related reoperations (Clavien-Dindo classification grade III) were noted for paraesophageal compared with axial hernias (2.1 vs $1.1 \% ; p=0.032)$ (Table 4). The main reasons for this were esophageal and gastric injuries, secondary bleeding, and abscesses.

For the general postoperative complications, a highly significant difference to the disadvantage of the paraesophageal hernias (types II-IV) was detected at 6.0 vs $3.0 \%(p<0.001)$ (Table 4). Since one-year follow-up was a precondition for patient selection, analysis did not take account of deaths. In the hiatal hernia operation group up to 1 September, 2015, including among patients without oneyear follow-up ( $n=1.086$ ) (Fig. 1), one death occurred in the axial (type I) hiatal hernia group (one out of 2792; $0.04 \%$ ) and three deaths in the paraesophageal (types IIIV) group (three out of $1.333 ; 0.22 \%$ ).

On one-year follow-up, no significant difference was identified in the recurrence rate or in the rates of pain at rest, on exertion or requiring treatment (Table 4). An additional analysis of patient outcome in relation to the individual hospital's case load showed no significant differences for a case load of 1-49, 50-99, and $\geq 100$ (Table 5).

\section{Multivariable analysis}

\section{Intraoperative complications}

The results of the model used for analysis of influencing factors for intraoperative complications are illustrated
Table 2 Comparison of mean age, mean BMI, mean procedure time, and mean defect size between axial and paraesophageal hiatal hernia types

\begin{tabular}{|c|c|c|c|c|}
\hline & & Type I & Types II-IV & $p$ \\
\hline Age (years) & Mean \pm STD & $55.4 \pm 14.0$ & $65.0 \pm 12.5$ & $<.001$ \\
\hline BMI & Mean \pm STD & $27.7 \pm 4.3$ & $28.7 \pm 4.8$ & $<.001$ \\
\hline Duration of procedure $(\min )^{\mathrm{a}}$ & MW (range) & $83.0(81.5 ; 84.6)$ & $104.4(102.8 ; 106.0)$ & $<.001$ \\
\hline Defect size $\left(\mathrm{cm}^{2}\right)^{\mathrm{a}}$ & MW (range) & $12.6(10.5 ; 14.8)$ & $21.5(19.2 ; 23.7)$ & $<.001$ \\
\hline
\end{tabular}

${ }^{a}$ Logarithmic transformation; indication of re-transformed mean and range of dispersion (mean-STD; mean + STD) 
Table 3 Comparison of demographic parameters, risk factors, and surgery-related parameters between axial and paraesophageal hiatal hernia types

\begin{tabular}{|c|c|c|c|c|c|}
\hline & \multicolumn{2}{|c|}{ Type I } & \multicolumn{2}{|c|}{ Types II-IV } & \multirow[t]{2}{*}{$p$} \\
\hline & $n$ & $\%$ & $n$ & $\%$ & \\
\hline \multicolumn{6}{|l|}{ Procedure } \\
\hline Fundophrenicopexy & 51 & 2.49 & 194 & 19.48 & \multirow[t]{3}{*}{$<.001$} \\
\hline Nissen & 845 & 41.28 & 394 & 39.56 & \\
\hline Toupet & 1151 & 56.23 & 408 & 40.96 & \\
\hline \multicolumn{6}{|l|}{ Hiatal repair technique } \\
\hline Suture & 1669 & 81.53 & 638 & 64.06 & \multirow[t]{3}{*}{$<.001$} \\
\hline Suture and mesh & 363 & 17.73 & 351 & 35.24 & \\
\hline Mesh & 15 & 0.73 & 7 & 0.70 & \\
\hline \multicolumn{6}{|l|}{ ASA score } \\
\hline $\mathrm{I}$ & 464 & 22.67 & 88 & 8.84 & \multirow[t]{4}{*}{$<.001$} \\
\hline II & 1302 & 63.61 & 561 & 56.33 & \\
\hline III & 277 & 13.5 & 339 & 34.0 & \\
\hline IV & 4 & 0.20 & 8 & 0.80 & \\
\hline \multicolumn{6}{|l|}{ Gender } \\
\hline Male & 898 & 43.87 & 327 & 32.83 & \multirow[t]{2}{*}{$<.001$} \\
\hline Female & 1149 & 56.13 & 669 & 67.17 & \\
\hline \multicolumn{6}{|l|}{ Risk factor } \\
\hline \multicolumn{6}{|l|}{ Total } \\
\hline Yes & 437 & 21.35 & 307 & 30.82 & \multirow[t]{2}{*}{$<.001$} \\
\hline No & 1610 & 78.65 & 689 & 69.18 & \\
\hline \multicolumn{6}{|l|}{ COPD } \\
\hline Yes & 168 & 8.21 & 137 & 13.76 & \multirow[t]{2}{*}{$<.001$} \\
\hline No & 1879 & 91.79 & 859 & 86.24 & \\
\hline \multicolumn{6}{|l|}{ Diabetes } \\
\hline Yes & 76 & 3.71 & 72 & 7.23 & \multirow[t]{2}{*}{$<.001$} \\
\hline No & 1971 & 96.29 & 924 & 92.77 & \\
\hline \multicolumn{6}{|l|}{ Aortic aneurysm } \\
\hline Yes & 5 & 0.24 & 8 & 0.80 & \multirow[t]{2}{*}{0.036} \\
\hline No & 2042 & 99.76 & 988 & 99.20 & \\
\hline \multicolumn{6}{|l|}{ Immunosuppression } \\
\hline Yes & 7 & 0.34 & 10 & 1.00 & \multirow[t]{2}{*}{0.034} \\
\hline No & 2040 & 99.66 & 986 & 99.00 & \\
\hline \multicolumn{6}{|l|}{ Corticoids } \\
\hline Yes & 20 & 0.98 & 19 & 1.91 & \multirow[t]{2}{*}{0.039} \\
\hline No & 2027 & 99.02 & 977 & 98.09 & \\
\hline \multicolumn{6}{|l|}{ Smoking } \\
\hline Yes & 162 & 7.91 & 58 & 5.82 & 0.037 \\
\hline No & 1885 & 92.09 & 938 & 94.18 & \\
\hline Coagulopathy & & & & & \\
\hline Yes & 13 & 0.64 & 16 & 1.61 & 0.015 \\
\hline No & 2034 & 99.36 & 980 & 98.39 & \\
\hline
\end{tabular}

Table 3 continued

\begin{tabular}{|c|c|c|c|c|c|}
\hline & \multicolumn{2}{|c|}{ Type I } & \multicolumn{2}{|c|}{ Types II-IV } & \multirow[t]{2}{*}{$p$} \\
\hline & $n$ & $\%$ & $n$ & $\%$ & \\
\hline \multicolumn{6}{|c|}{ Antiplatelet medication } \\
\hline Yes & 62 & 3.03 & 68 & 6.83 & \multirow[t]{2}{*}{$<.001$} \\
\hline No & 1985 & 96.97 & 928 & 93.17 & \\
\hline \multicolumn{6}{|c|}{ Anticoagulation therapy } \\
\hline Yes & 21 & 1.03 & 15 & 1.51 & \multirow[t]{2}{*}{0.284} \\
\hline No & 2026 & 98.97 & 981 & 98.49 & \\
\hline \multicolumn{6}{|c|}{ Symptoms } \\
\hline \multicolumn{6}{|c|}{ Reflux } \\
\hline Yes & 1827 & 89.25 & 657 & 65.96 & \multirow[t]{2}{*}{$<.001$} \\
\hline No & 220 & 10.75 & 339 & 34.04 & \\
\hline \multicolumn{6}{|c|}{ Regurgitation } \\
\hline Yes & 491 & 23.99 & 275 & 27.61 & \multirow[t]{2}{*}{0.033} \\
\hline No & 1556 & 76.01 & 721 & 72.39 & \\
\hline \multicolumn{6}{|c|}{ Dysphagia } \\
\hline Yes & 392 & 19.15 & 454 & 45.58 & \multirow[t]{2}{*}{$<.001$} \\
\hline No & 1655 & 80.85 & 542 & 54.42 & \\
\hline \multicolumn{6}{|l|}{ Pain } \\
\hline Yes & 763 & 37.27 & 484 & 48.59 & \multirow[t]{2}{*}{$<.001$} \\
\hline No & 1284 & 62.73 & 512 & 51.41 & \\
\hline \multicolumn{6}{|c|}{ Anemia/bleeding } \\
\hline Yes & 81 & 3.96 & 212 & 21.29 & \multirow[t]{2}{*}{$<.001$} \\
\hline No & 1966 & 96.04 & 784 & 78.71 & \\
\hline \multicolumn{6}{|c|}{ Affection of lung } \\
\hline Yes & 163 & 7.96 & 159 & 15.96 & \multirow[t]{2}{*}{$<.001$} \\
\hline No & 1884 & 92.04 & 837 & 84.04 & \\
\hline
\end{tabular}

in Fig. 2 (model matching: $p<0.001$ ). The risk of intraoperative complications was primarily influenced by the ASA score $(p=0.001)$. A lower ASA score (I vs II: 0.195 [0.076; 0.497]; I vs III/IV: 0.144 [0.050; 0.409] reduced the risk of intraoperative complications. Likewise, age and operative technique had a significant influence on the intraoperative complications. Accordingly, by comparison, a 10-year-older patient had a significantly lower intraoperative complication risk (10-year OR 0.799 [0.676; 0.944]). On the other hand, the complication risk was increased when the Nissen compared with the Toupet method was used (OR 1.849 [1.202; 2.842]; $p=0.005$ ).

\section{Surgical postoperative complications}

Model matching for analysis of the postoperative complications, which reflects the suitability of the influence 
Table 4 Comparison of intraoperative, postoperative, and general complications and 1-year follow-up outcome between axial and paraesophageal hiatal hernia types

$\begin{array}{llll}\text { Type I } & & \text { Types II-IV } & \\ & \% & \mathrm{n} & \%\end{array}$

Intraoperative complications

Total

Yes

No

60

1987

2.93

97.07

Intraop.: bleeding

Yes

No

28

2019

Injuries

Total

$$
\text { Yes }
$$

No

2000

Esophagus

Yes

No

Stomach

$$
\text { Yes }
$$

No

Bowel

Yes

No

Liver

Yes

No

Spleen

Yes

No

Vessel

$$
\text { Yes }
$$

No

Others (pleura opening, diaphragm injury)

Yes

No

26

2021

Postoperative complications (Clavien-Dindo classification grades I-III)

Total

Yes

No

Bleeding

Yes

No

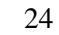

2023

3

2044

Esophageal perforation

Yes 10

No 2037

Infection

$$
\text { Yes }
$$

No

3
2044

1.37

98.63

2.30

97.70

0.05

99.95

0.10

99.90

0.00

100.0

0.39

99.61

0.39

99.61

0.15

99.85

1.27

98.73

1.17

98.83

0.15

99.85

0.49

99.51

0.15

99.85
41

955

14

982

37

959

3.71

96.29

0.00

100.0

996

0.50

99.50

0.10

99.90

0.30

99.70

0.70

99.30

0.20

99.80

994

21

975

2.11

97.89
0.105

1.000

8.59

0.033

1.000

0.042

1.000

0.274

0.665

0.086

2.01
97.99

0.50

0.123

991

99.50

0.50

1.000

991

99.50

0.60

99.40

0.076

6

990

0.067

Stomach perforation 
Table 4 continued

\begin{tabular}{|c|c|c|c|c|c|}
\hline & \multicolumn{2}{|c|}{ Type I } & \multicolumn{2}{|c|}{ Types II-IV } & \multirow[t]{2}{*}{$p$} \\
\hline & $n$ & $\%$ & $\mathrm{n}$ & $\%$ & \\
\hline Yes & 5 & 0.24 & 0 & 0.00 & 0.180 \\
\hline No & 2042 & 99.76 & 996 & 100.0 & \\
\hline \multicolumn{6}{|c|}{ Wound healing disorder } \\
\hline Yes & 3 & 0.15 & 6 & 0.60 & 0.067 \\
\hline No & 2044 & 99.85 & 990 & 99.40 & \\
\hline \multicolumn{6}{|l|}{ Ileus } \\
\hline Yes & 0 & 0.00 & 2 & 0.20 & 0.107 \\
\hline No & 2047 & 100.0 & 994 & 99.80 & \\
\hline \multicolumn{6}{|c|}{ General complications } \\
\hline \multicolumn{6}{|c|}{ Total } \\
\hline Yes & 61 & 2.98 & 60 & 6.02 & $<.001$ \\
\hline No & 1986 & 97.02 & 936 & 93.98 & \\
\hline \multicolumn{6}{|l|}{ Fever } \\
\hline Yes & 6 & 0.29 & 7 & 0.70 & 0.137 \\
\hline No & 2041 & 99.71 & 989 & 99.30 & \\
\hline \multicolumn{6}{|c|}{ Urinary voiding problems } \\
\hline Yes & 4 & 0.20 & 5 & 0.50 & 0.163 \\
\hline No & 2043 & 99.80 & 991 & 99.50 & \\
\hline \multicolumn{6}{|c|}{ Diarrhea } \\
\hline Yes & 1 & 0.05 & 1 & 0.10 & 0.548 \\
\hline No & 2046 & 99.95 & 995 & 99.90 & \\
\hline \multicolumn{6}{|c|}{ Gastritis } \\
\hline Yes & 1 & 0.05 & 1 & 0.10 & 0.548 \\
\hline No & 2046 & 99.95 & 995 & 99.90 & \\
\hline \multicolumn{6}{|c|}{ Thrombosis } \\
\hline Yes & 2 & 0.10 & 0 & 0.00 & 1.000 \\
\hline No & 2045 & 99.90 & 996 & 100.0 & \\
\hline \multicolumn{6}{|c|}{ Pulmonary embolism } \\
\hline Yes & 1 & 0.05 & 3 & 0.30 & 0.106 \\
\hline No & 2046 & 99.95 & 993 & 99.70 & \\
\hline \multicolumn{6}{|c|}{ Pleural effusion } \\
\hline Yes & 10 & 0.49 & 17 & 1.71 & 0.001 \\
\hline No & 2037 & 99.51 & 979 & 98.29 & \\
\hline \multicolumn{6}{|c|}{ Pneumonia } \\
\hline Yes & 6 & 0.29 & 12 & 1.20 & 0.004 \\
\hline No & 2041 & 99.71 & 984 & 98.80 & \\
\hline \multicolumn{6}{|c|}{ COPD (clinical exacerbation) } \\
\hline Yes & 7 & 0.34 & 7 & 0.70 & 0.251 \\
\hline No & 2040 & 99.66 & 989 & 99.30 & \\
\hline \multicolumn{6}{|c|}{ Cardiac insufficiency } \\
\hline Yes & 4 & 0.20 & 10 & 1.00 & 0.003 \\
\hline No & 2043 & 99.80 & 986 & 99.00 & \\
\hline \multicolumn{6}{|c|}{ Coronary heart disease } \\
\hline Yes & 5 & 0.24 & 4 & 0.40 & 0.486 \\
\hline No & 2042 & 99.76 & 992 & 99.60 & \\
\hline
\end{tabular}


Table 4 continued

\begin{tabular}{|c|c|c|c|c|c|}
\hline & \multicolumn{2}{|c|}{ Type I } & \multicolumn{2}{|c|}{ Types II-IV } & \multirow[t]{2}{*}{$p$} \\
\hline & $n$ & $\%$ & $\mathrm{n}$ & $\%$ & \\
\hline \multicolumn{6}{|c|}{ Myocardial infarction } \\
\hline Yes & 1 & 0.05 & 2 & 0.20 & 0.251 \\
\hline No & 2046 & 99.95 & 994 & 99.80 & \\
\hline \multicolumn{6}{|c|}{ Renal insufficiency } \\
\hline Yes & 2 & 0.10 & 0 & 0.00 & 1.000 \\
\hline No & 2045 & 99.90 & 996 & 100.0 & \\
\hline \multicolumn{6}{|c|}{ Hypertensive crisis } \\
\hline Yes & 3 & 0.15 & 4 & 0.40 & 0.226 \\
\hline No & 2044 & 99.85 & 992 & 99.60 & \\
\hline \multicolumn{6}{|c|}{ Complication-related reoperation (Clavien-Dindo classification grade III) } \\
\hline Yes & 22 & 1.07 & 21 & 2.11 & 0.032 \\
\hline No & 2025 & 98.93 & 975 & 97.89 & \\
\hline \multicolumn{6}{|c|}{ Recurrence on 1-year follow-up } \\
\hline Yes & 105 & 5.13 & 40 & 4.02 & 0.204 \\
\hline No & 1942 & 94.87 & 956 & 95.98 & \\
\hline \multicolumn{6}{|c|}{ Pain on exertion on 1-year follow-up } \\
\hline Yes & 222 & 10.85 & 102 & 10.24 & 0.661 \\
\hline No & 1825 & 89.15 & 894 & 89.76 & \\
\hline \multicolumn{6}{|c|}{ Pain at rest on 1-year follow-up } \\
\hline Yes & 180 & 8.79 & 86 & 8.63 & 0.945 \\
\hline No & 1867 & 91.21 & 910 & 91.37 & \\
\hline \multicolumn{6}{|c|}{ Pain requiring treatment on 1 -year follow-up } \\
\hline Yes & 166 & 8.11 & 71 & 7.13 & 0.387 \\
\hline No & 1881 & 91.89 & 925 & 92.87 & \\
\hline
\end{tabular}

Table 5 Outcome of patients depending on hospitals case load

\begin{tabular}{|c|c|c|c|c|c|c|c|}
\hline & \multicolumn{2}{|c|}{$1-49$ OPs } & \multicolumn{2}{|c|}{ 50-99 OPs } & \multicolumn{2}{|c|}{$>100 \mathrm{OPs}$} & \multirow[b]{2}{*}{$p$} \\
\hline & $n$ & $\%$ & $n$ & $\%$ & $n$ & $\%$ & \\
\hline \multicolumn{8}{|c|}{ Intraoperative complications } \\
\hline Yes & 51 & 3.46 & 10 & 2.56 & 40 & 3.39 & 0.701 \\
\hline No & 1421 & 96.54 & 381 & 97.44 & 1140 & 96.61 & \\
\hline \multicolumn{8}{|c|}{ Postoperative complications (Clavien-Dindo classification grade I-III) } \\
\hline Yes & 24 & 1.63 & 8 & 2.05 & 12 & 1.02 & 0.199 \\
\hline No & 1448 & 98.37 & 383 & 97.95 & 1168 & 98.98 & \\
\hline \multicolumn{8}{|c|}{ General complications } \\
\hline Yes & 63 & 4.28 & 10 & 2.56 & 48 & 4.07 & 0.299 \\
\hline No & 1409 & 95.72 & 381 & 97.44 & 1132 & 95.93 & \\
\hline \multicolumn{8}{|c|}{ Recurrence on 1-year follow-up } \\
\hline Yes & 82 & 5.57 & 11 & 2.81 & 52 & 4.41 & 0.053 \\
\hline No & 1390 & 94.43 & 380 & 97.19 & 1128 & 95.59 & \\
\hline
\end{tabular}

parameters to explain the outcome variable scores, was not significant $(p=0.335)$. As such, there was no evidence of the individual variables having significantly influenced the postoperative complication rate.

\section{Complication-related reoperations}

Model matching for complication-related reoperations, which reflects the suitability of the influence parameters to 
Fig. 2 Forest plot: Multivariable analysis of influencing factors for intraoperative complications in hiatal hernia repair

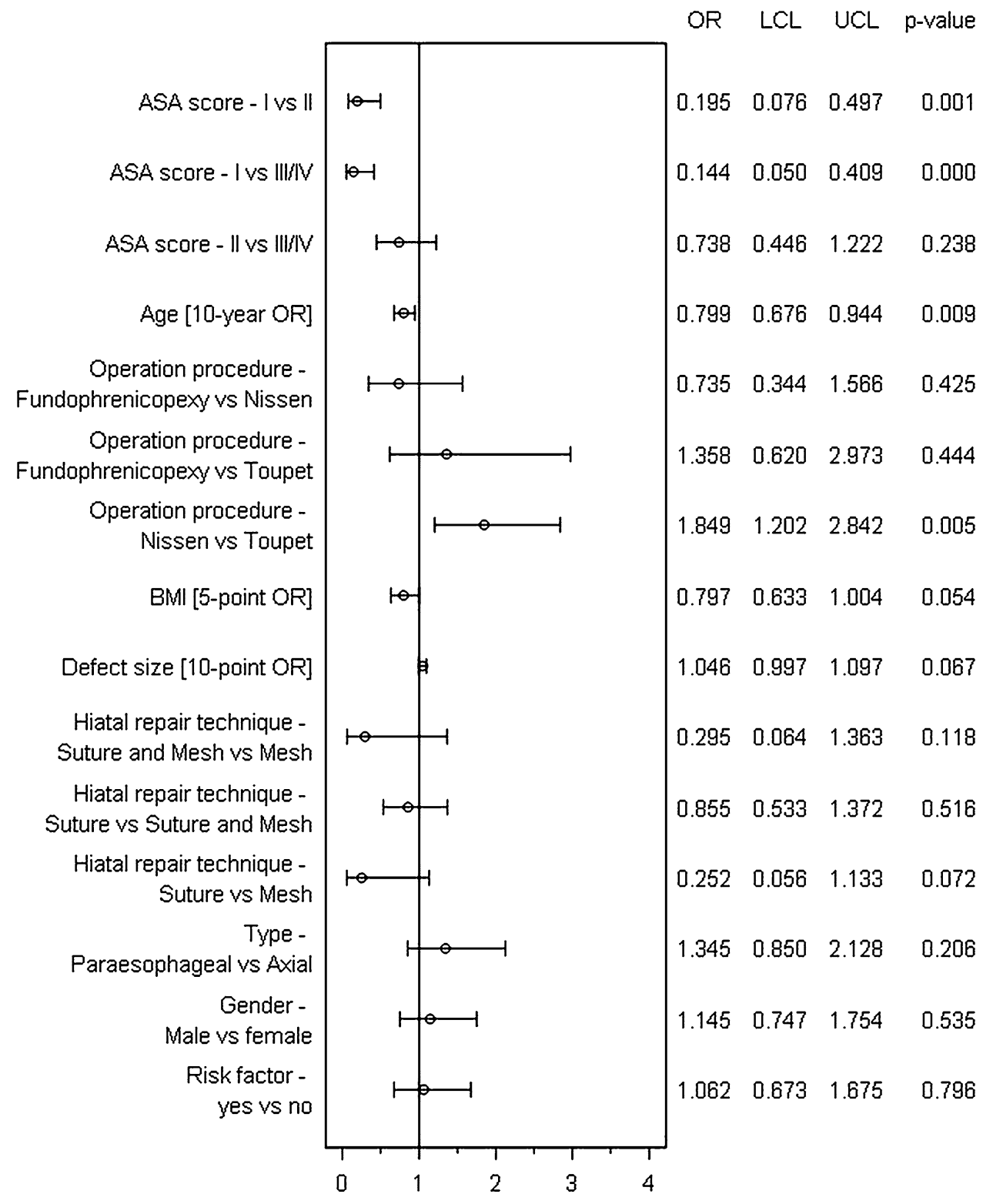

explain the outcome variable scores, was not significant ( $p=0.249$ ). As such, there was no evidence of the individual variables having significantly influenced the complication-related reoperation rate.

\section{General postoperative complications}

The results of the model used for analysis of the general postoperative complication rate are shown in Fig. 3 (model matching: $p<0.001)$. Onset of general postoperative complications was primarily affected by the presence of risk factors $(p=0.006)$. The presence of at least one risk factor increased the general postoperative complication risk (OR 1.767 [1.180; 2.646]). Older patients, too, had an increased risk of general postoperative complications (10year OR 1.255 [1.055; 1.494]). Conversely, the general postoperative complication risk was reduced in cases of hiatoplasty with suture alone compared with suture and mesh (OR 0.552 [0.371;0.822]; $p=0.003$ ).

\section{Recurrence on one-year follow-up}

Model matching for recurrence on one-year follow-up, which reflects the suitability of the influence parameters to explain the outcome variable scores, was not significant $(p=0.180)$. As such, there was no evidence of the 

Multivariable analysis of influencing factors for general postoperative complications following hiatal hernia repair
Fig. 3 Forest plot:

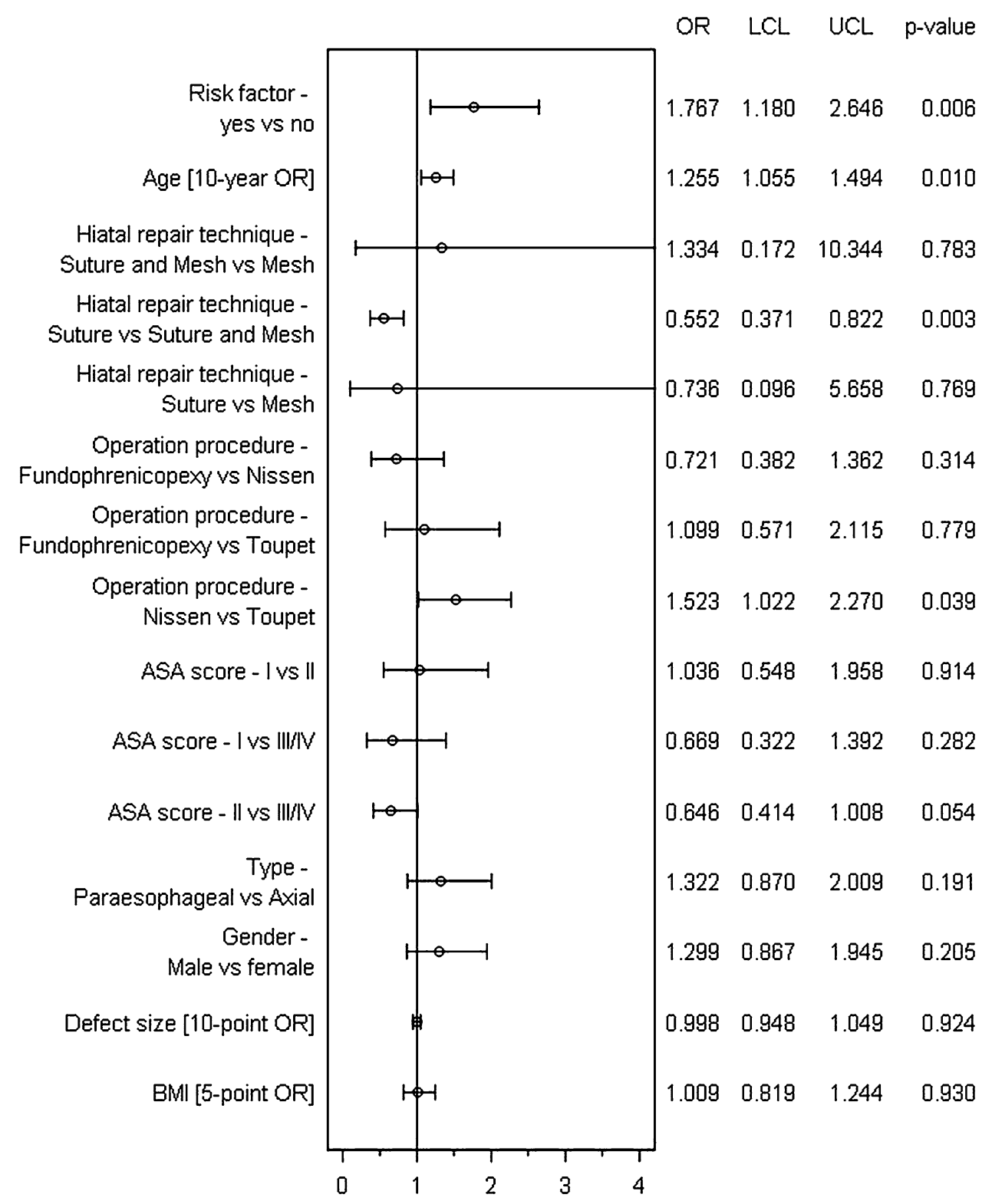

individual variables having significantly influenced the recurrence rate.

\section{Pain at rest on one-year follow-up}

The results of the model used for analysis of pain at rest on one-year follow-up are summarized subsequently (model matching: $p=0.002$ ). This was significantly impacted by risk factors, gender, and BMI. The rate was increased if there was at least one risk factor (OR 1.512 [1.135; 2.014]; $p=0.005$ ). On the other hand, men (OR 0.664 [0.499; $0.864] ; p=0.005)$ and patients with higher BMI (5-point OR 0.821 [0.709; 0.951; $p=0.009$ ) had a lower risk of pain at rest.

\section{Pain on exertion on follow-up}

Model matching for pain on exertion on one-year followup, which reflects the suitability of the influence parameters to explain the outcome variable scores, was not significant ( $p=0.154)$. As such, there was no evidence of the individual variables having significantly influenced the pain on exertion rate.

\section{Chronic pain requiring treatment on one-year follow-up}

The results of the model used for analysis of chronic pain requiring treatment are summarized subsequently (model 
matching: $p=0.022$ ). These, too, were significantly influenced by risk factors, gender, and BMI. The presence of at least one risk factor (OR 1.515 [1.119; 2.051]; $p=0.007)$ increased the risk of chronic pain requiring treatment. On the other hand, men (OR 0.712 [0.527; $0.961] ; p=0.026)$ and patients with higher BMI (5-point OR 0.839 [0.718; 0.981]; $p=0.028$ ) had a lower risk of chronic pain requiring treatment.

\section{Discussion}

This paper analyzes prospective data from the Herniamed Registry for 3043 patients with primary, elective, and laparoscopic repair of a hiatal hernia. Only patients with complete one-year follow-up results were included in the analysis. Since the outcome for patients with axial hiatal hernia and reflux disease differs greatly from that of patients with paraesophageal hiatal hernia, due to divergent patient characteristics and complexity of the repair technique, the two patient collectives were compared in the analysis presented here.

First of all, significant differences were noted in the patient characteristics. Patients with paraesophageal hernia were on average almost 10 years older, had a somewhat higher BMI, larger hernia defect, and tended more often to be female. The chief determinant for onset of significantly more perioperative complications among patients with paraesophageal hiatal hernia was a higher proportion of patients with ASA scores III/IV (34.8 vs 13.7\%; $p<0.0001)$ and of patients with risk factors (30.8 vs $21.4 \% ; p<0.001)$.

Both these factors help to explain the significantly more frequent onset of general postoperative complications after repair of paraesophageal compared with axial hiatal hernias (6.0 vs $3.0 \% ; p<0.001)$. Multivariable analysis clearly demonstrates that the presence of at least one risk factor and higher age significantly increases the risk of general postoperative complications.

The greater complexity of the procedures used for paraesophageal hiatal hernia repair is reflected in a significantly higher intraoperative organ injury rate (3.7 vs $2.3 \% ; p=0.033)$ and significantly higher rate of complication-related reoperations $(2.1$ vs $1.1 \% ; p=0.033)$ compared with axial hiatal hernias.

The recurrence rate on one-year follow-up for patients after laparoscopic repair of axial hiatal hernias was 5.1\% and for paraesophageal hiatal hernias it was $4.0 \%$ $(p=0.204)$, with the proportion of mesh-augmented hiatoplasties being significantly higher (35.2 vs $17.7 \%$; $p<0.001$ ) for paraesophageal hiatal hernias. The indication for mesh use was decided by the individual surgeon or hospital. The specific reasons for using a mesh were not documented.

Multivariable analysis did not find any evidence that the use of a mesh or other factors had a significant influence on the recurrence rate on one-year follow-up. That concords with the meta-analysis of four randomized controlled trials with 406 patients by Memom et al. [16]. It can only be speculated whether the significantly more frequent use of meshes for types II-IV hiatal hernias with highly significantly larger hiatal defects had led to a non-significant difference in the recurrence rate. In less than $1 \%$ of cases, only a mesh and no suture was used for hiatal closure, as reported in the literature [21]. That practice is not recommended in the guidelines [4].

There was no significant difference in the rates of pain at rest, pain on exertion, or pain requiring treatment on oneyear follow-up between the patients after laparoscopic repair of axial (type I) vs paraesophageal (types II-IV) hiatal hernia.

Multivariable analysis demonstrates that the risk of pain at rest and pain requiring treatment was higher in the presence of risk factors, and was lower among men and in patients with higher BMI.

In summary, patients with elective laparoscopic repair of primary paraesophageal (types II-IV) vs axial (type I) hiatal hernia were found to have a significantly higher risk of general postoperative complications because of higher age and higher ASA score as well as the higher proportion of patients with at least one risk factor. Reflecting the greater complexity of laparoscopic paraesophageal (types II-IV) hiatal hernia repair procedures, there is greater likelihood of significantly more intraoperative organ injuries and postoperative complication-related reoperations. Accordingly, laparoscopic procedures for repair of paraesophageal (types II-IV) hiatal hernias should only be undertaken by experienced surgeons. Because of the higher risk of general postoperative complications, corresponding intensive medicine resources are needed.

Acknowledgements Ferdinand Köckerling-Grants to fund the Herniamed Registry from Johnson \& Johnson, Norderstedt, Karl Storz, Tuttlingen, pfm medical, Cologne, Dahlhausen, Cologne, B Braun, Tuttlingen, MenkeMed, Munich and Bard, Karlsruhe.

\section{Compliance with ethical standards}

Disclosures Y. Trommer, K. Zarras, D. Adolf, B. Kraft, D. Weyhe, R. Fortelny, C. Schug-Paß have no conflicts of interest or financial ties to disclose.

Open Access This article is distributed under the terms of the Creative Commons Attribution 4.0 International License (http://crea tivecommons.org/licenses/by/4.0/), which permits unrestricted use, distribution, and reproduction in any medium, provided you give appropriate credit to the original author(s) and the source, provide a 
link to the Creative Commons license, and indicate if changes were made.

\section{Herniamed Study Group}

\section{Scientific Board}

Köckerling, Ferdinand (Chairman) (Berlin); Bittner, Reinhard (Rottenburg); Fortelny, René (Wien); Jacob, Dietmar (Berlin); Koch, Andreas (Cottbus); Kraft, Barbara (Stuttgart); Kuthe, Andreas (Hannover); Lippert, Hans (Magdeburg): Lorenz, Ralph (Berlin); Mayer, Franz (Salzburg); Moesta, Kurt Thomas (Hannover); Niebuhr, Henning (Hamburg); Peiper, Christian (Hamm); Pross, Matthias (Berlin); Reinpold, Wolfgang (Hamburg); Simon, Thomas (Weinheim); Stechemesser, Bernd (Köln); Unger, Solveig (Chemnitz), Weyhe, Dirk (Oldenburg).

\section{Participants}

Ahmetov, Azat (Saint-Petersburg); Alapatt, Terence Francis (Frankfurt/Main); Albayrak, Nurretin (Herne); Amann, Stefan (Neuendettelsau); Anders, Stefan (Berlin); Anderson, Jürina (Würzburg); Antoine, Dirk (Leverkusen); Apfelstedt, Heinrich (Solingen); Arndt, Anatoli (Elmshorn); Aschenbrenner, Michael (Spittal/Drau); Asperger, Walter (Halle); Avram, Iulian (Saarbrücken); BaikogluEndres, Corc (Weißenburg i. Bay.); Bandowsky, Boris (Damme); Barkus; Jörg (Velbert); Becker, Matthias (Freital); Behrend, Matthias (Deggendorf); Beuleke, Andrea (Burgwedel); Berger, Dieter (Baden-Baden); Birk, Dieter (Bietigheim-Bissingen); Bittner, Reinhard (Rottenburg); Blaha, Pavel (Zwiesel); Blumberg, Claus (Lübeck); Böckmann, Ulrich (Papenburg); Böhle, Arnd Steffen (Bremen); Bolle, Ludger (Berlin); Borchert, Erika (Grevenbroich); Born, Henry (Leipzig); Brabender, Jan (Köln); Breitenbuch von, Philipp (Radebeul); Brož, Miroslav (Ebersbach); Brückner, Torsten (Gießen); Brütting, Alfred (Erlangen); Buchert, Annette (Mallersdorf-Pfaffenberg; Buchholz, Torsten (Aurich; Budzier, Eckhard (Meldorf); Burchett, Bert (Teterow); Burghardt, Jens (Rüdersdorf); Cejnar, Stephan-Alexander (München); Chirikov, Ruslan (Dorsten); Claußnitzer, Christian (Ulm); Comman, Andreas (Bogen); Crescenti, Fabio (Verden/ Aller); Daniels, Thies (Hamburg); Dapunt, Emanuela (Bruneck); Decker, Georg (Berlin); Demmel, Michael (Arnsberg); Descloux, Alexandre (Baden); Deusch, KlausPeter (Wiesbaden); Dick, Marcus (Neumünster); Dieterich, Klaus (Ditzingen); Dietz, Harald (Landshut); Dittmann, Michael (Northeim); Drummer, Bernhard (Forchheim); Eckermann, Oliver (Luckenwalde); Eckhoff, Jörn/
Hamburg); Ehmann, Frank (Grünstadt); Eisenkrein, Alexander (Düren); Elger, Karlheinz (Germersheim); Engelhardt, Thomas (Erfurt); Erichsen, Axel (Friedrichshafen); Eucker, Dietmar (Bruderholz); Fackeldey, Volker (Kitzingen); Farke, Stefan (Delmenhorst); Faust, Hendrik (Emden); Federmann, Georg (Seehausen); Feichter, Albert (Wien); Fiedler, Michael (Eisenberg); Fikatas, Panagiotis (Berlin); Firl, Michaela (Perleberg); Fischer, Ines (Wiener Neustadt); Fleischer, Sabine (Dinslaken); Fortelny, René H. (Wien); Franczak, Andreas (Wien); Franke, Claus (Düsseldorf); Frankenberg von, Moritz (Salem); Frehner, Wolfgang (Ottobeuren); Friedhoff, Klaus (Andernach); Friedrich, Jürgen (Essen); Frings, Wolfram (Bonn); Fritsche, Ralf (Darmstadt); Frommhold, Klaus (Coesfeld); Frunder, Albrecht (Tübingen); Fuhrer, Günther (Reutlingen); Gassler, Harald (Villach); Gawad, Karim A. Frankfurt/Main); Gehrig, Tobias (Sinsheim); Gerdes, Martin (Ostercappeln); Germanov, German (Halberstadt; Gilg, Kai-Uwe (Hartmannsdorf); Glaubitz, Martin (Neumünster); Glauner-Goldschmidt, Kerstin (Werne); Glutig, Holger (Meissen); Gmeiner, Dietmar (Bad Dürnberg); Göring, Herbert (München); Grebe, Werner (Rheda-Wiedenbrück); Grothe, Dirk (Melle); Günther, Thomas (Dresden); Gürtler, Thomas (Zürich); Hache, Helmer (Löbau); Hämmerle, Alexander (Bad Pyrmont); Haffner, Eugen (Hamm); Hain, Hans-Jürgen (Gross-Umstadt); Hammans, Sebastian (Lingen); Hampe, Carsten (Garbsen); Hanke, Stefan (Halle); Harrer, Petra (Starnberg); Hartung, Peter (Werne); Heinzmann, Bernd (Magdeburg); Heise, Joachim Wilfried (Stolberg); Heitland, Tim (München); Helbling, Christian (Uznach/Schweiz); Hellinger, Achim (Fulda); Hempen, Hans-Günther (Cloppenburg); Henneking, KlausWilhelm (Bayreuth); Hennes, Norbert (Duisburg); Hermes, Wolfgang (Weyhe); Herrgesell, Holger (Berlin); Herzing, Holger Höchstadt); Hessler, Christian (Bingen); Heuer, Matthias (Herten); Hildebrand, Christiaan (Langenfeld); Höferlin, Andreas (Mainz); Hoffmann, Henry (Basel); Hoffmann, Michael (Kassel); Hofmann, Eva M. (Frankfurt/ Main); Horbach, Thomas (Fürth); Hornung, Frederic (Wolfratshausen); Hudak, Attila (Suhl); Hübel-Abe, Jan (Ilmenau; Hügel, Omar (Hannover); Hüttemann, Martin (Oberhausen); Hüttenhain, Thomas (Mosbach); Hunkeler, Rolf (Zürich); Imdahl, Andreas (Heidenheim); Isemer, Friedrich-Eckart (Wiesbaden); Jablonski, Herbert Gustav (Sögel); Jacob, Dietmar (Berlin); Jansen-Winkeln, Boris (Leipig); Jantschulev, Methodi (Waren); Jenert, Burghard (Lichtenstein); Jugenheimer, Michael (Herrenberg); Junge, Karsten (Aachen); Junger, Marc (München); Kaaden, Stephan (Neustadt am Rübenberge); Käs, Stephan (Weiden); Kahraman, Orhan (Hamburg); Kaiser, Christian (Westerstede); Kaiser, Gernot Maximilian (Kamp-Lintfort); Kaiser, Stefan (Kleinmachnow); Kapischke, Matthias (Hamburg); Karch, Matthias (Eichstätt); Kasparek, 
Michael S. (München); Keck, Heinrich (Wolfenbüttel); Keller, Hans W. (Bonn); Kienzle, Ulrich (Karlsruhe); Kipfmüller, Brigitte (Köthen); Kirsch, Ulrike (Oranienburg); Klammer, Frank (Ahlen); Klatt, Richard (Hagen); Klein, Karl-Hermann (Burbach); Kleist, Sven (Berlin); Klobusicky, Pavol (Bad Kissingen); Kneifel, Thomas (Datteln); Knoop, Michael (Frankfurt/Oder); Knotter, Bianca (Mannheim); Koch, Andreas (Cottbus); Koch, Andreas (Münster); Köckerling, Ferdinand (Berlin); Köhler, Gernot (Linz); König, Oliver (Buchholz); Kornblum, Hans (Tübingen); Krämer, Dirk (Bad Zwischenahn); Kraft, Barbara (Stuttgart); Kratsch, Barthel (Dierdorf/Selters); Krausbeck, Matthias (Schwerin); Kreissl, Peter (Ebersberg); Krones, Carsten Johannes (Aachen); Kronhardt, Heinrich (Neustadt am Rübenberge); Kruse, Christinan (Aschaffenburg); Kube, Rainer (Cottbus); Kühlberg, Thomas (Berlin); Kühn, Gert (Freiberg); Kuhn, Roger (Gifhorn); Kusch, Eduard (Gütersloh); Kuthe, Andreas (Hannover); Ladberg, Ralf (Bremen); Ladra, Jürgen (Düren); Lahr-Eigen, Rolf (Potsdam); Lainka, Martin (Wattenscheid); Lammers, Bernhard J. (Neuss); Lancee, Steffen (Alsfeld); Lange, Claas (Berlin); Langer, Claus (Göttingen); Laps, Rainer (Ehringshausen); Larusson, Hannes Jon (Pinneberg); Lauschke, Holger (Duisburg); Lechner-Puschnig, Marina (Klagenfurt am Wörthersee/ Österreich); Leher, Markus (Schärding); Leidl, Stefan (Waidhofen/Ybbs); Leisten, Edith (Köln); Lenz, Stefan (Berlin); Liedke, Marc Olaf (Heide); Lienert, Mark (Duisburg); Limberger, Andreas (Schrobenhausen); Limmer, Stefan (Würzburg); Locher, Martin (Kiel); Loghmanieh, Siawasch (Viersen); Lorenz, Ralph (Berlin); Luther, Stefan (Wipperfürth); Luyken, Walter (SulzbachRosenberg); Mallmann, Bernhard (Krefeld); Manger, Regina (Schwabmünchen); Maurer, Stephan (Münster); May, Jens Peter (Schönebeck); Mayer, Franz (Salzburg); Mayer, Jens (Schwäbisch Gmünd); Mellert, Joachim (Höxter); Menzel, Ingo (Weimar); Meurer, Kirsten (Bochum); Meyer, Moritz (Ahaus); Mirow, Lutz (Kirchberg); Mittag-Bonsch, Martina (Crailsheim); Mittenzwey, Hans-Joachim (Berlin); Möbius, Ekkehard (Braunschweig), Mörder-Köttgen, Anja (Freiburg); Moesta, Kurt Thomas (Hannover); Moldenhauer, Ingolf (Braunschweig); Morkramer, Rolf (Radevormwald); Mosa, Tawfik (Merseburg); Müller, Hannes (Schlanders); Münzberg, Gregor (Berlin); Murr, Alfons (Vilshofen); Mussack, Thomas (St. Gallen); Nartschik, Peter (Quedlinburg); Nasifoglu, Bernd (Ehingen); Neumann, Jürgen (Haan); Neumeuer, Kai (Paderborn); Niebuhr, Henning (Hamburg); Nix, Carsten (Walsrode); Nölling, Anke (Burbach); Nostitz, Friedrich Zoltán (Mühlhausen); Obermaier, Straubing); Öz-Schmidt, Meryem (Hanau); Oldorf, Peter (Usingen); Olivieri, Manuel (Pforzheim); Passon, Marius (Freudenberg); Pawelzik, Marek (Hamburg); Pein, Tobias (Hameln); Peiper,
Christian (Hamm); Peiper, Matthias (Essen); Pertl, Alexander (Spittal/Drau); Philipp, Mark (Rostock); Pickart, Lutz (Bad Langensalza); Pizzera, Christian (Graz); Pöllath, Martin (Sulzbach-Rosenberg); Pöschmann, Enrico (Thalwil); Possin, Ulrich (Laatzen); Prenzel, Klaus (Bad Neuenahr-Ahrweiler); Pröve, Florian (Goslar); Pronnet, Thomas (Fürstenfeldbruck); Pross, Matthias (Berlin); Puff, Johannes (Dinkelsbühl); Rabl, Anton (Passau); Raggi, Matthias Claudius (Stuttgart); Rapp, Martin (Neunkirchen); Reck, Thomas (Püttlingen); Reinpold, Wolfgang (Hamburg); Renter, Marc Alexander (Moers); Reuter, Christoph (Quakenbrück); Richter, Jörg (Winnenden); Riemann, Kerstin (Alzenau-Wasserlos); Riesener, Klaus-Peter (Marl); Rodehorst, Anette (Otterndorf); Roehr, Thomas (Rödental); Rössler, Michael (Rüdesheim am Rhein); Roncossek, Bremerhaven); Rosniatowski, Rolland (Marburg); Roth Hartmut (Nürnberg); Sardoschau, Nihad (Saarbrücken); Sauer, Gottfried (Rüsselsheim); Sauer, Jörg (Arnsberg); Seekamp, Axel (Freiburg); Seelig, Matthias (Bad Soden); Seidel, Hanka (Eschweiler); Seiler, Christoph Michael (Warendorf); Seltmann, Cornelia (Hachenburg); Senkal, Metin (Witten); Shamiyeh, Andreas (Linz); Shang, Edward (München); Siemssen, Björn (Berlin); Sievers, Dörte (Hamburg); Silbernik, Daniel (Bonn); Simon, Thomas (Weinheim); Sinn, Daniel (Olpe); Sinner, Guy (Merzig); Sinning, Frank (Nürnberg); Smaxwil, Constatin Aurel (Stuttgart); Sörensen, Björn (Lauf an der Pegnitz): Syga, Günter (Bayreuth); Schabel, Volker (Kirchheim/Teck); Schadd, Peter (Euskirchen); Schassen von, Christian (Hamburg); Schattenhofer, Thomas (Vilshofen); Scheidbach, Hubert (Neustadt/Saale); Schelp, Lothar (Wuppertal); Scherf, Alexander (Pforzheim); Scheuerlein, Hubert (Paderborn); Scheyer, Mathias (Bludenz); Schilling, André (Kamen); Schimmelpenning, Hendrik (Neustadt in Holstein); Schinkel, Svenja (Kempten); Schmid, Michael (Gera); Schmid, Thomas (Innsbruck); Schmidt, Ulf (Mechernich); Schmitz, Heiner (Jena); Schmitz, Ronald (Altenburg); Schöche, Jan (Borna); Schoenen, Detlef (Schwandorf); Schrittwieser, Rudolf (Bruck an der Mur); Schroll, Andreas (München); Schubert, Daniel (Saarbrücken); Schüder, Gerhard (Wertheim); Schürmann, Rainer (Steinfurt); Schultz, Christian (Bremen-Lesum); Schultz, Harald (Landstuhl); Schulze, Frank P. Mülheim an der Ruhr); Schulze, Thomas (Dessau-Roßlau); Schumacher, Franz-Josef (Oberhausen); Schwab, Robert (Koblenz); Schwandner, Thilo (Lich); Schwarz, Jochen Günter (Rottenburg); Schymatzek, Ulrich (Eitorf); Spangenberger, Wolfgang (Bergisch-Gladbach); Sperling, Peter (Montabaur); Staade, Katja (Düsseldorf); Staib, Ludger (Esslingen); Staikov, Plamen (Frankfurt am Main); Stamm, Ingrid (Heppenheim); Stark, Wolfgang (Roth); Stechemesser, Bernd (Köln); Steinhilper, Uz (München); Stengl, Wolfgang (Nürnberg); Stern, Oliver (Hamburg); Stöltzing, 
Oliver (Meißen); Stolte, Thomas (Mannheim); Stopinski, Jürgen (Schwalmstadt); Stratmann, Gerald (Goch); Straßburger, Harald (Alfeld); Stubbe, Hendrik (Güstrow/); Stülzebach, Carsten (Friedrichroda); Tepel, Jürgen (Osnabrück); Terzić, Alexander (Wildeshausen); Teske, Ulrich (Essen); Thasler, Wolfgang (München); Tichomirow, Alexej (Brühl); Tillenburg, Wolfgang (Marktheidenfeld); Timmermann, Wolfgang (Hagen); Tomov, Tsvetomir (Koblenz; Train, Stefan H. (Gronau); Trauzettel, Uwe (Plettenberg); Triechelt, Uwe (Langenhagen); Ulbricht, Wolfgang (Breitenbrunn); Ulcar, Heimo (Schwarzach im Pongau); Ungeheuer, Andreas (München); Unger, Solveig (Chemnitz); Verweel, Rainer (Hürth); Vogel, Ulrike (Berlin); Voigt, Rigo (Altenburg); Voit, Gerhard (Fürth); Volkers, Hans-Uwe (Norden); Volmer, Ulla (Berlin); Vossough, Alexander (Neuss); Wallasch, Andreas (Menden); Wallner, Axel (Lüdinghausen); Warscher, Manfred (Lienz); Warwas, Markus (Bonn); Weber, Jörg (Köln); Weber, Uwe (Eggenfelden); Weihrauch, Thomas (Ilmenau); Weiß, Johannes (Schwetzingen); Weißenbach, Peter (Neunkirchen); Werner, Uwe (Lübbecke-Rahden); Wessel, Ina (Duisburg); Weyhe, Dirk (Oldenburg); Wieber, Isabell (Köln); Wiens, Matthias (Affoltern); Wiesmann, Aloys (Rheine); Wiesner, Ingo (Halle); Withöft, Detlef (Neutraubling); Woehe, Fritz (Sanderhausen); Wolf, Claudio (Neuwied); Wolkersdörfer, Toralf (Pößneck); Yaksan, Arif (Wermeskirchen); Yildirim, Can (Lilienthal); Yildirim, Selcuk (Berlin); Zarras, Konstantinos (Düsseldorf); Zeller, Johannes (WaldshutTiengen); Zhorzel, Sven (Agatharied); Zuz, Gerhard (Leipzig).

\section{References}

1. Draaisma WA, Gooszen HG, Tournoij E, Broeders IAMJ (2005) Controversies in paraesophageal hernia repair. Surg Endosc 19:1300-1308. doi:10.1007/s00464-004-2275-3

2. Fuchs KH, Babic B, Breithaupt W, Dallemagne B, Fingerhut A, Furnée E, Granderath F, Horvath P, Kardos P, Pointner R, Savarino E, Van Herwaarden-Lindeboom M (2014) EAES recommendations for the management of gastroesophageal reflux disease. Surg Endosc 28:1753-1773. doi:10.1007/s00464-014-3431-z

3. Kohn GP, Price RR, DeMeester SR, Zehetner J, Muensterer OJ, Awad Z, Mittal SK, Richardson WS, Stefanidis D, Fanelli RD, for the SAGES Guidelines Committee (2013) Guidelines for the management of hiatal hernia. Surg Endosc 27:4409-4428. doi:10. 1007/s00464-013-3173-3

4. Stefanidis D, Hope WW, Kohn GP, Reardon PR, Richardson WS, Fanelli RD, The SAGES, Committee Guidelines (2010) Guidelines for surgical treatment of gastroesophageal reflux disease. Surg Endosc 24:2647-2669. doi:10.1007/s00464-010-1267-8

5. Iwakiri K, Kinoshita Y, Habu Y, Oshima T, Manabe N, Fujiwara Y, Nagahara A, Kawamura O, Iwakiri R, Ozawa S, Ashida K, Ohara S, Kashiwagi H, Adachi K, Higuchi K, Miwa H, Fujimoto K, Kasano Y, Kawano T, Haruma K, Hongo M, Sugano K, Watanabe M, Shimosegawa T (2016) Evidence-based clinical practice guidelines for gastroesophageal reflux disease 2015 . J Gastroenterol 51:751-767. doi:10.1007/s00535-016-1227-8

6. Peters MJ, Mukhtar A, Yunus RM, Khan S, Pappalardo J, Memon B, Memon MA (2009) Meta-analysis of randomized clinical trials comparing open and laparoscopic anti-reflux surgery. Am J Gastroenterol 104:1548-1561. doi:10.1038/ajg.2009.176

7. Broeders JA, Roks DJ, Ali UA, Draaisma WA, Smout AJ, Hazebroek EJ (2011) Laparoscopic anterior versus posterior fundoplication for gastroesophageal reflux disease. Ann Surg 254:39-47. doi:10.1097/SLA.0b013e31821d4ba0

8. Tian ZC, Wang B, Shan CX, Zhang W, Jiang DZ, Qiu M (2015) A meta-analysis of randomized controlled trials to compare longterm outcomes of Nissen and Toupet fundoplication for gastroesophageal reflux disease. PLoS ONE. doi:10.1371/journal. pone. 0127627

9. Broeders JAJL, Mauritz FA, Ali UA, Draaisma WA, Ruurda JP, Gooszen HG, Smout AJPM, Broeders IAMJ, Hazebroek EJ (2010) Systematic review and meta-analysis of laparoscopic Nissen (posterior total) versus Toupet (posterior partial) fundoplication for gastro-oesophageal reflux disease. BJS 97:1318-1330. doi:10.1002/bjs.7174

10. Müller-Stich BP, Kenngott HG, Gondan M, Stock C, Linke GR, Fritz F, Nickel F, Diener MK, Gutt CN, Wente M, Büchler MW, Fischer L (2015) Use of mesh in laparoscopic paraesophageal hernia repair: a meta-analysis and risk-benefit analysis. PLoS ONE. doi:10.1371/journal.pone.0139547

11. Antoniou SA, Antoniou GA, Koch OO, Pointner R, Granderath FA (2012) Lower recurrence rates after mesh-reinforced versus simple hiatal hernia repair: a meta-analysis of randomized trials. Surg Laparosc Endosc Percutan Tech 22(6):498-502

12. Antoniou SA, Koch OO, Antoniou GA, Pointner R, Granderath FA (2012) Mesh-reinforced hiatal hernia repair: a review on the effect on postoperative dysphagia and recurrence. Langenbecks Arch Surg 397:19-27. doi:10.1007/s00423-011-0829-0

13. Furnée E, Hazebroek E (2013) Mesh in laparoscopic large hiatal hernia repair: a systematic review of the literature. Surg Endosc 27:3998-4008. doi:10.1007/s00464-013-3036-y

14. Antoniou SA, Müller-Stich BP, Antoniou GA, Köhler G, Luketina RR, Koch OO, Pointner R, Granderath FA (2015) Laparoscopic augmentation of the diaphragmatic hiatus with biologic mesh versus suture repair: a systematic review and meta-analysis. Langenbecks Arch Surg 400:577-583. doi:10.1007/s00423-015$1312-0$

15. Huddy JR, Markar SR, Ni MZ, Morino M, Targarona EM, Zaninotto G, Hanna GB (2016) Laparoscopic repair of hiatus hernia: does mesh type influence outcome? A meta-analysis and European survey study. Surg Endosc 30(12):5209-5221. doi:10. 1007/s00464-016-4900-3

16. Memon MA, Memon B, Yunus RM, Khan S (2016) Suture cruroplasty versus prosthetic hiatal herniorrhaphy for large hiatal hernia. Ann Surg 263(2):258-266. doi:10.1097/SLA.00000000 00001267

17. Tam V, Winger DG, Nason KS (2016) A systematic review and meta-analysis of mesh vs suture cruroplasty in laparoscopic large hiatal hernia repair. Am J Surg 211:226-238. doi:10.1016/j.amj surg.2015.07.007

18. Terry M, Smith CD, Branum GD, Galloway K, Waring JP, Hunter JG (2001) Outcomes of laparoscopic fundoplication for gastroesophageal reflux disease and paraesophageal hernia. Surg Endosc 15:691-699. doi:10.1007/s004640080144

19. Stechemesser B, Jacob DA, Schug-Paß C, Köckerling F (2012) Herniamed: an internet-based registry for outcome research in hernia surgery. Hernia 16(3):269-276. doi:10.1007/s10029-0120908-3

20. Baucom RB, Ousley J, Feurer ID, Beveridge GB, Pierce RA, Holzman MD, Sharp KW, Poulose BK (2016) Patient reported 
outcomes after incisional hernia repair-establishing the ventral hernia recurrence inventory. Am J Surg 212:81-88. doi:10.1016/ j.amjsurg.2015.06.007
21. Kelty et al (2006) Controversial topics in surgery. Ann R Coll Surg Engl 89:479-483. doi:10.1308/003588407X202182 